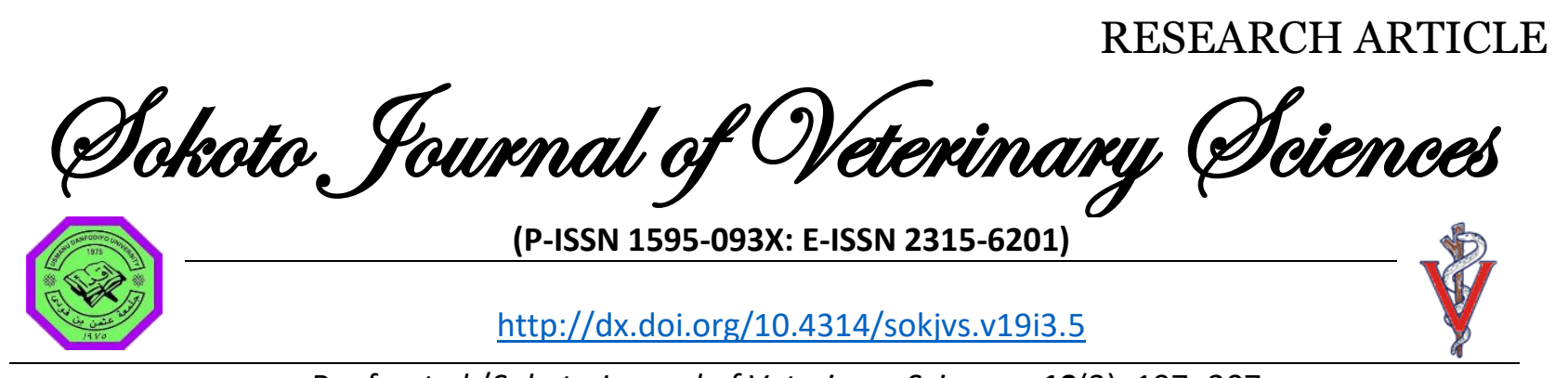

Raufu et al./Sokoto Journal of Veterinary Sciences, 19(3): 197- 207.

\title{
Molecular characterization of Salmonella enterica from poultry farms in Ilorin, north-central Nigeria
}

\author{
IA Raufu ${ }^{1,2 *}$, OA Ahmed ${ }^{1}$, A Aremu ${ }^{3}$, JA Ameh ${ }^{4} \&$ A Ambali ${ }^{5}$ \\ 1. Department of Veterinary Microbiology, University of Ilorin, Ilorin, Nigeria \\ Departments of Animal Sciences Dairy Science, University of Wisconsin-Madison, 1675 Observatory \\ Dr., Madison, WI, 53706, USA \\ 3. Department of Veterinary Pharmacology and Toxicology, University of Ilorin, Ilorin, Nigeria \\ 4. Department of Veterinary Microbiology, University of Abuja, Abuja, Nigeria \\ 5. Department of Veterinary Medicine, University of Ilorin, Ilorin, Nigeria
}

*Correspondence: Tel.: +2348038135235; E-mail: raufuib@yahoo.com

\begin{abstract}
Copyright: (C) 2021
Raufu et al. This is an open-access article published under the terms of the Creative Commons Attribution License which permits unrestricted use, distribution, and reproduction in any medium, provided the original author and source are credited.
\end{abstract}

Publication History: Received: 02-02-2021 Revised: 01-05-2021 Accepted: 12-05-2021

\begin{abstract}
Poultry salmonellosis caused by Salmonella enterica is one of the most important bacterial diseases posing serious challenges to poultry production and human health worldwide. This study investigated the occurrence, serotypes, multilocus sequence types (MLSTs), antimicrobial resistance, plasmids, and 12 selected virulence genes of non-typhoidal Salmonella from poultry layer farms using whole-genome sequencing (WGS) methods. Two hundred cloaca swab samples were aseptically collected from four commercial poultry farms (layers) and transferred in sterile universal bottles on ice to the laboratory for analysis. Presumptive Salmonella isolates were detected with selective media and conventional biochemical tests. Serovars were confirmed by serotyping using the slide agglutination and Seqsero methods. Seven samples were positive for Salmonella consisting of Salmonella Typhimurium $(S$. Typhimurium) $(n=4)$, $S$. Albany $(n=2)$, and $S$. Agama with an occurrence rate of $3.5 \%(7 / 200)$. Overall, 3 isolates showed the parC mutation expected not to cause resistance. Similarly, one $S$. Typhimurium isolate carried plasmid replicons of IncFIB(S)/IncFII(S) type without antimicrobial resistance genes. Three sequence types (STs); 19 (S. Typhimurium), 5317 (S. Albany), and 467 (S. Agama) were obtained. Salmonella Agama harboured 12 virulence genes, while $S$. Typhimurium and $S$. Albany harboured 11 virulence genes each. This study highlights the importance of S. Typhimurium, S. Albany, and S. Agama as major pathogens associated with poultry farms in Ilorin, north-central Nigeria. It equally provided baseline information on the serovar distribution, STs, resistance and the virulence gene profiles of all the serovars. Therefore, chickens can serve as a potential source of Salmonella transmission to humans, and this constitutes a potential health risk to the human population. Hence, there is a need for a specific Salmonella control program to be instituted as part of a national food safety strategy.
\end{abstract}




\section{Introduction}

Over 2,600 Salmonella enterica serovars have been reported (Achtman et al., 2012). However, the majority of infections are caused by a very limited number of serovars, which may differ from one country to another and over time (Hendriksen et al., 2011; Van et al., 2012). Salmonella enterica subsp. enterica serovars Enteritidis and Typhimurium are the most commonly reported serovars associated with human salmonellosis globally (Hendriksen et al., 2011).

Salmonellosis in poultry is of global concern because it is commonly accompanied with morbidity, mortality, and significant economic losses (Abiodun et al., 2014; Ahmed et al., 2017). The disease can be transmitted vertically from parents to offsprings and horizontally on farms, thus, making its control a challenge. Infection by the horizontal route could be via infected litter, water, dust, faeces, feed, equipment, fomites, and rodents harbouring Salmonella (Raufu et al., 2019). Therefore, humans are susceptible to contracting salmonellosis through the consumption of contaminated poultry products (Whiley \& Ross, 2015).

The poultry sub-division of agriculture constitutes the most commercialized division in Nigeria, and the sector has transformed the lives of low-income farmers positively in a production system with little capital investment and low costs of technology. Furthermore, the sector has contributed an average of 454 billion tonnes of meat and 3.8 million eggs annually to the national economy with an approximate population of 180 million birds (Food and Agriculture Organization, 2018). Salmonella is among the major causes of human foodborne illnesses worldwide; however, little is known about its occurrence and genomic characteristics in most developing countries. Poultry and other food animals are regarded as common reservoirs of Salmonella enterica. Furthermore, undercooked poultry products have been identified as a major source of human infection with non-typhoidal Salmonella (Foley et al., 2011). It has been reported that commonly isolated Salmonella serovars in a given location are usually among the most prevalent serovars associated with human infections, thus emphasizing the significance of Salmonella colonization of poultry farms to public health (Hendriksen et al., 2011; Yang et al., 2019). Therefore, the knowledge of Salmonella serovars distribution in food animals and humans is of value in investigating the course of Salmonella epidemiology and to identify serovars that cluster over time and space (Eguale, 2018).
The global burden of human diarrheal disease caused by Salmonella gastro-enteric infections is estimated at 93.8 million cases per year and 155,000 deaths (Majowicz et al., 2010). Salmonellosis is specifically frequent among children in developing countries including Nigeria, where they often go unreported due to lack of a foodborne pathogens surveillance program. Apart from causing diarrheal disease, Salmonella has been implicated in invasive bloodstream infections, specifically in sub-Saharan Africa (Feasey et al., 2012).

The emergence and spread of antimicrobial resistance among zoonotic Salmonella have become a public health concern in several developing countries due to the unregulated use of antibiotics for therapeutics and as poultry feed additives, which has led to the emergence of multidrug-resistant Salmonella (Ed-dra et al., 2017). Furthermore, the development of antimicrobial resistance is often associated with the overuse and misuse of antimicrobials in veterinary and human medicine, especially in developing countries.

Resistance genes can spread from Salmonella in food animals to humans through mobile genetic elements (MGEs), such as plasmids, integrons and transposons that harbour resistance genes (Emond-Rheault et al., 2020; Kudirkiene et al., 2018). These mobile elements, especially the plasmids, may spread rapidly from multidrug-resistant clones of Salmonella within human and animal hosts (Carattoli, 2013; Hoffmann et al., 2017).

In recent times, Salmonella strains with clinically important resistance to some agents like extendedspectrum cephalosporins and fluoroquinolones have been recovered from livestock (Li et al., 2013). Previous reports have documented the relevance of the relatedness between nalidixic acid resistance and reduced susceptibility to fluoroquinolones in Salmonella (McDermott et al., 2016). Therefore, it is imperative to investigate the mechanism of quinolone resistance in foodborne Salmonella, which could be traced to the occurrence of foodborne outbreaks and the subsequent problem of clinical therapy.

Different serovars are associated with different disease potentials, making serotype determination very necessary for epidemiological surveillance and disease assessment (Achtman et al., 2012). Serotyping has been used for the epidemiological investigation of Salmonella by conventional serological methods based on White Kauffmann Le Minor scheme which classified Salmonella into over 
2,600 serovars (Fagbamila et al., 2017). Recently, sequence-based techniques such as Multi Locus Sequence Typing (MLST) and Whole Genome Sequencing (WGS) have been proposed as a replacement for serotyping to identify evolutionary and epidemiological relatedness (Ashton et al., 2016; Robertson et al., 2018). Such methods assign serotypes by using freely available in silico pipelines such as SeqSero, which utilizes surface antigenencoding genes to predict serotypes (Zhang et al., 2019).

Plasmid sequencing remains the main strategy for complete plasmid characterization. In recent times, plasmid extraction from whole-genome sequences is becoming increasingly common, and to date, a few bioinformatic tools have been developed for in silico detection and characterization of plasmids in wholegenome sequences (Arredondo-Alonso et al., 2017; Orlek et al., 2017).

The pathogenicity of Salmonella strains is related to various virulence genes harboured within the Salmonella pathogenicity islands (SPIs). These genes include hilA and invA that are located in SPI, which allows Salmonella to invade epithelial cells.

Furthermore, Salmonella outer proteins encoded by sop gene is also relevant to Salmonella virulence (Huehn et al., 2010). Similarly, plasmid-encoded fimbriae genes (e.g. pefA) enhance the adhesion of
Salmonella to epithelial cells (Murugkar et al., 2003). This study investigates the occurrence, serotypes, multilocus sequence types (STs), antimicrobial resistance, plasmids and virulence profiles of nontyphoidal Salmonella isolated from poultry farms in Ilorin, north-central Nigeria.

\section{Materials and Methods}

Study area/farms and sample collection

Four commercial poultry farms (layers) located at Egbejila, Eiyenkorin, and Lasoju communities in Ilorin, Kwara State, Nigeria (Figure 1), were visited for sample collection. The state lies on an elevation of 305 meters above sea level with a population of $2,591,555$. Its coordinates are latitudes $\left(8^{\circ} 30^{\prime} \mathrm{N}\right)$ and longitudes $\left(5^{\circ} 00^{\prime} \mathrm{E}\right)$. The state shares a common internal boundary with Niger state in the north, Kogi state in the east, Oyo, Ekiti and Osun states in the south and an international border with the Republic of Benin in the west. The state has an annual rainfall range of $1,000 \mathrm{~mm}$ to $1,500 \mathrm{~mm}$. Seasonal rain begins at the end of March and ends in early September. The dry season is from early October to early March.

Each farm was visited three times (once in two months) for sample collection, and each of the farms was visited on each sampling occasion.

The birds were managed intensively in battery cages, with each farm raising between 5,000 to 15,000 birds. The average age of the flocks ranged between 65 and

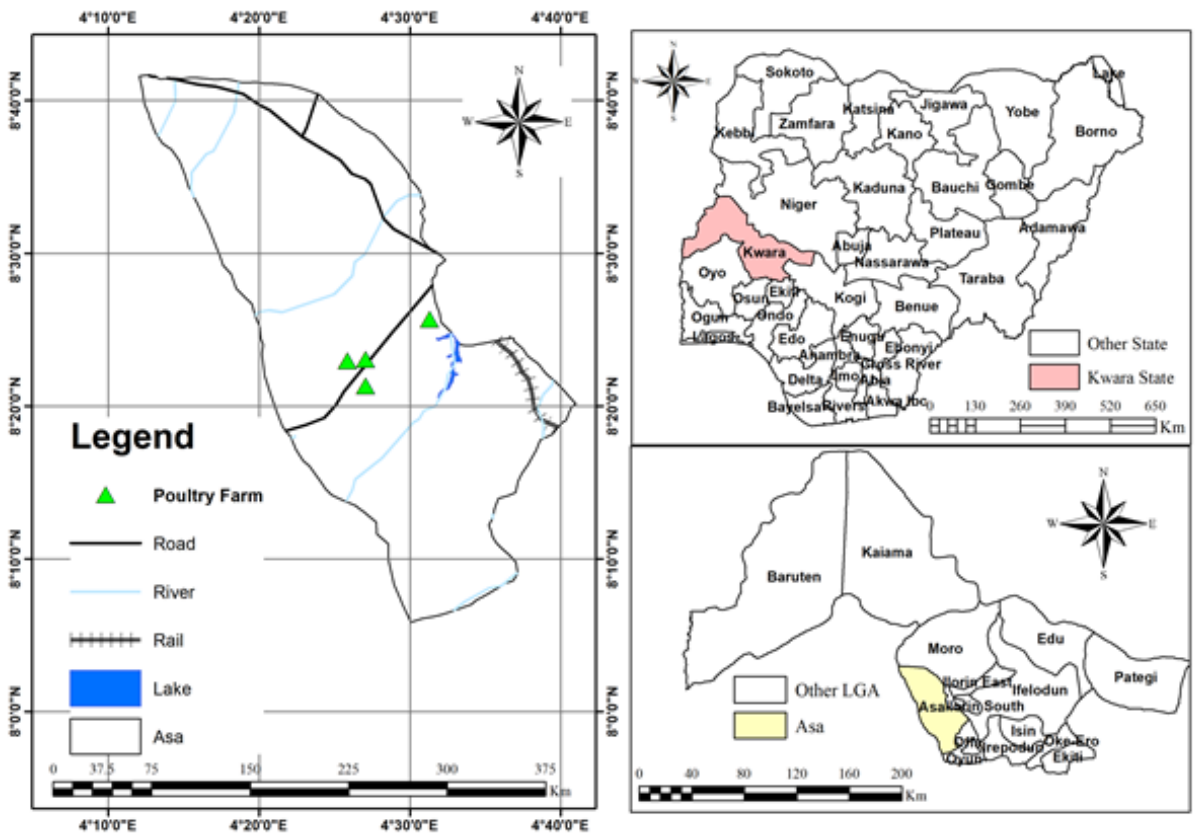

Figure 1: Map of Ilorin showing study area and farms for sample collection
80 weeks old (approximately 73 weeks old) at the start of our sampling. The farms obtained their day-old chicks from two different hatcheries located in a neighbouring state and obtained their feed supply from reputable feed mills. Twenty cloacal samples were collected from each farm on the first and second visits and ten samples each were collected on the final sampling day. Cloacal swabs were aseptically collected with a sterile 
commercial swab, immediately into a sterile sample bottle, and transported to the laboratory on ice for analysis.

Isolation and identification of Salmonella species Samples were pre-enriched in buffered peptone water (Oxoid, Hampshire, UK) at a ratio of $1: 10$ sample to broth and incubated aerobically at $37^{\circ} \mathrm{C}$ for 24 hours. One milliliter of the pre-enriched broth culture was inoculated into $9.0 \mathrm{ml}$ of Selenite-F broth swab (Fluka Biochemika, Steinheim, Germany) and incubated aerobically for $18-24$ hours at $37^{\circ} \mathrm{C}$. The broth was streaked on Salmonella Shigella agar (Laboratarios Britania, Buenos Aires, Argentina) and incubated for $18-24$ hours at $37^{\circ} \mathrm{C}$. Black colonies were sub-cultured on Xylose Lysine Deoxycholate (XLD) agar (Oxoid, Hampshire, UK) and incubated aerobically for $18-24$ hours at $37^{\circ} \mathrm{C}$. Presumptive Salmonella isolates on XLD with pink/red color and dark center were confirmed by standard biochemical tests and stored on nutrient agar slants for serotyping at the World Health Organization (WHO) National Salmonella and Shigella Center, Bangkok, Thailand according to the Kauffmann-White Scheme as previously described (Raufu et al., 2009).

\section{Whole Genome Sequence (WGS) data collection}

Two hundred Salmonella isolates were shipped on nutrient agar slants to U.S. Food and Drug Administration, College Park, Maryland, USA, for WGS analysis. According to the manufacturer's instructions, bacterial DNA was extracted from overnight cultures using the DNeasy blood and tissue kit (Qiagen, Valencia, CA, USA). Sequencing libraries were constructed with $0.2 \mathrm{ng} / \mu \mathrm{l}$ of prepared DNA immediately uploaded to FDA's GenomeTrakr database (Allard et al., 2016), hosted within NCBI Pathogen Detection (NCBI Resource Coordinators, 2017) under the bioproject PRJNA186035. The SRA accession numbers and assembly statistics of all the Salmonella enterica serovars are shown in Table 1.

\section{Whole Genome Sequence (WGS) analysis}

Raw data were subjected to genome assembly using SPAdes version 3.8 (Bankevich et al., 2012), and genome annotation was performed with the NCBI Prokaryotic Genome Annotation Pipeline (PGAP) (Tatusova et al., 2016). Salmonella serotyping by whole-genome sequencing was predicted with the SeqSero version 1.0 software tool (Zhang et al., 2015). Resistance determinants in the ResFinder and PointFinder databases were identified in assemblies using starAMR v. 0.4.0. Plasmid genes were identified using Abricate v. 0.8.10 (Seemann, 2015) and a modified version of the PlasmidFinder database (Zankari et al., 2012). Predicted resistance phenotypes were assigned by using the determinants detected and the ResFinder and PointFinder drug keys developed by the Centers for Disease Control and Prevention (Feldgarden et al., 2019).

Multilocus sequence types (MLST) were determined by WGS based on sequencing of the seven housekeeping genes: aroC, dnaN, hemD, hisD, purE, sucA, and thrA. The contig sequence files were uploaded to the Centre for Genomic Epidemiology MLST database. In silico multilocus sequence typing (MLST) data were extracted from the Center for Genomic Epidemiology online tool (Larsen et al., 2012) to assign sequence type (ST) to each study isolate based on the set of alleles derived from the aforementioned seven loci. The virulence genes present in the genome were extracted from the Public Health Agency of Canada website (Chen et al., 2016).

\section{Results}

Analysis of genomic data obtained from WGS showed the total lengths of genomes ranged from 4.6 to 4.9 $\mathrm{Mb}, \mathrm{G}+\mathrm{C}$ average content ranges from 51.70 to 52.20 $\%$, the numbers of contigs range from 32 to 74 . The numbers of coding genes, noncoding RNAs (ncRNAs), tRNAs, (CRISPR) arrays, genome coverage, number of CDS (total), rRNA (complete) and the contig N50 ranges from 4,266 to $4,674,10$ to 14,60 to 73 , and 2 to $3,64 x$ to $131 x, 4,350$ to $4,765,3(58)$ to $6(58)$ and 175, 261 to 303, 664, respectively (Table 1 ).

Out of 200 samples, seven samples were positive for Salmonella (Table 2). Three serovars were represented: Salmonella Typhimurium (S. Typhimurium) ( $n=4)$, S. Albany $(n=2)$, and S. Agama $(n=1)$. Three sequence types (STs) were obtained from WGS analysis, these are ST-19, 467, and 5317 exhibited by S. Typhimurium, S. Agama, and S. Albany respectively (Table 2 ).

Genotypic antimicrobial susceptibility results showed three isolates; $S$. Albany $(n=2)$ and $S$. Agama $(n=1)$ to have a single T57S mutation in the parC gene alone. All the four S. Typhimurium strains lacked resistance determinants but one encoded IncFIB(S)/IncFII(S) plasmid replicons (Table 2 ).

Twelve virulence genes were identified across several virulence loci consisting of SP-1, 2, 3, 5, 11, and chromosomal encoded sifA gene. The genes investigated include: SP-1; InvA, SipB, prgH, avrA, SPI2; ssaR, ssaB/spiC, SPI-3; misL, mgtB, SPI-5; PipB, sopB, SPI-11; CdtB. Only Salmonella Agama harbored each of the 12 identified virulence genes (Table 3). 
Table 1: Assembly statistics of Salmonella enterica serovars isolated from poultry farms in llorin, Nigeria

\begin{tabular}{|c|c|c|c|c|c|c|c|c|c|c|c|c|c|c|}
\hline \multirow[t]{2}{*}{ Sample ID } & \multirow{2}{*}{$\begin{array}{l}\text { Salmonella } \\
\text { serovar }\end{array}$} & \multirow{2}{*}{$\begin{array}{l}\text { GenBank } \\
\text { accession No. }\end{array}$} & \multirow{2}{*}{$\begin{array}{l}\text { Biosample } \\
\text { accession No. }\end{array}$} & \multicolumn{5}{|c|}{ Genome size } & \multirow{2}{*}{$\begin{array}{l}\text { No. of } \\
\text { CDS } \\
\text { (total) }\end{array}$} & \multirow{2}{*}{$\begin{array}{l}\text { No of } \\
\text { coding } \\
\text { genes }\end{array}$} & \multirow{2}{*}{$\begin{array}{l}\text { rRNA } \\
\text { (complete) }\end{array}$} & \multirow[t]{2}{*}{ tRNA } & \multirow{2}{*}{$\begin{array}{l}\mathrm{nc} \\
\text { RNA }\end{array}$} & \multirow{2}{*}{$\begin{array}{l}\text { CRISPR } \\
\text { Arrays }\end{array}$} \\
\hline & & & & $\begin{array}{l}\text { Length } \\
\text { (bp) }\end{array}$ & $\begin{array}{l}\text { No. of } \\
\text { Contigs }\end{array}$ & $\begin{array}{l}\text { Coverage } \\
\text { (x) }\end{array}$ & $\begin{array}{l}\mathrm{G}+\mathrm{C} \\
(\%) \\
\text { contents }\end{array}$ & $\begin{array}{l}\text { Contig } \\
\text { N50 }\end{array}$ & & & & & & \\
\hline CFSAN083238 & Typhimurium & GCA_006007725.1 & PDS000039015.6 & $4,859,818$ & 67 & $131 x$ & $51.70 \%$ & 178,292 & 4,725 & 4,632 & $3(5 S)$ & 61 & 14 & 3 \\
\hline CFSAN083242 & Typhimurium & GCA_006147495.1 & PDS000039015.6 & $4,858,370$ & 72 & $94 x$ & $51.80 \%$ & 175,261 & 4,734 & 4,642 & $3(5 S)$ & 64 & 11 & 2 \\
\hline CFSAN083253 & Typhimurium & GCA_006147355.1 & PDS000039015.6 & $4,890,353$ & 64 & $102 x$ & $51.90 \%$ & 181,079 & 4,765 & 4,674 & $3(5 S)$ & 62 & 12 & 3 \\
\hline CFSAN083257 & Typhimurium & GCA_006081075.1 & PDS000039015.6 & $4,829,700$ & 66 & $91 x$ & $52.00 \%$ & 175,364 & 4,688 & 4,595 & $3(5 S)$ & 60 & 11 & 3 \\
\hline CFSAN083241 & Albany & GCA_006080655.1 & PDS000038995.2 & $4,680,993$ & 42 & $102 x$ & $51.60 \%$ & 237,090 & 4,471 & 4,370 & $5(5 S)$ & 61 & 10 & 2 \\
\hline CFSAN083276 & Albany & GCA_005902125.1 & PDS000038995.2 & $4,656,289$ & 32 & $106 x$ & $52.20 \%$ & 303,664 & 4,532 & 4,532 & $6(5 S)$ & 73 & 10 & 2 \\
\hline CFSAN083240 & Agama & GCA_006294055.1 & PDS000039006.4 & $4,586,567$ & 47 & $103 x$ & $51.70 \%$ & 214,188 & 4,350 & 4,266 & $4(5 S)$ & 64 & 11 & 2 \\
\hline
\end{tabular}

Table 2: Serotypes, antimicrobial resistance, plasmids and MLST types of Salmonella serovars from poultry farms in llorin, North-central Nigeria

\begin{tabular}{|c|c|c|c|c|c|c|c|c|}
\hline Sample ID No. & $\begin{array}{l}\text { NCBI-SRA SRA } \\
\text { Run No. }\end{array}$ & $\begin{array}{c}\text { Primary Taxonomy } \\
\text { Hit }\end{array}$ & $\begin{array}{l}\text { Predicted } \\
\text { Serotype }\end{array}$ & SeqSero2(JC) & MLST & $\begin{array}{l}\text { Resistance } \\
\text { Determinants }\end{array}$ & Plasmids & $\begin{array}{l}\text { Anticipated } \\
\text { Resistance }\end{array}$ \\
\hline CFSAN083238 & SRR9163976 & Salmonella enterica & Typhimurium & Typhimurium & 19 & None & None & None \\
\hline CFSAN083242 & SRR9164963 & Salmonella enterica & Typhimurium & Typhimurium & 19 & None & None & None \\
\hline CFSAN083253 & SRR9164982 & Salmonella enterica & Typhimurium & Typhimurium & 19 & None & $\begin{array}{l}\operatorname{IncFIB}(S) / \\
\operatorname{lncFII}(S)^{\ddagger}\end{array}$ & None \\
\hline CFSAN083257 & SRR9164977 & Salmonella enterica & Typhimurium & Typhimurium & 19 & None & None & None \\
\hline CFSAN083241 & SRR9163974 & Salmonella enterica & Albany & Albany & 5317 & $\operatorname{parC}(\mathrm{T} 57 \mathrm{~S})$ & None & None \\
\hline CFSAN083276 & SRR8266852 & Salmonella enterica & Albany & Albany & 5317 & $\operatorname{parC}(\mathrm{T} 57 \mathrm{~S})$ & None & None \\
\hline CFSAN083240 & SRR9163977 & Salmonella enterica & Agama & Agama & 467 & $\operatorname{parC}(\mathrm{T} 57 \mathrm{~S})$ & None & None \\
\hline
\end{tabular}

Key: $\quad \ddagger=$ single plasmid with two replicons 
Table 3: Virulence genes of Salmonella serovars from cloaca swabs of chickens from poultry farms in llorin, north-central Nigeria

\begin{tabular}{|c|c|c|c|c|c|c|c|c|c|}
\hline \multirow[b]{2}{*}{ 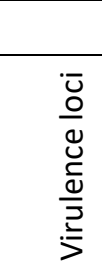 } & \multirow[b]{2}{*}{$\begin{array}{l}\mathbb{D} \\
\frac{U}{U} \\
0\end{array}$} & \multicolumn{8}{|c|}{ Salmonella serotypes } \\
\hline & & 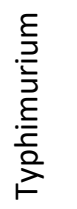 & 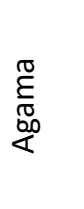 & 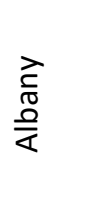 & 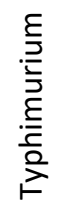 & 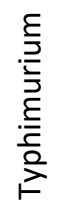 & 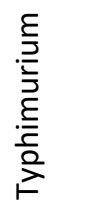 & 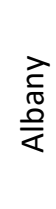 & \\
\hline \multicolumn{10}{|c|}{ SPI-1 } \\
\hline & $\operatorname{InvA}$ & + & + & + & + & + & + & & + \\
\hline & $\operatorname{Sip} B$ & + & + & + & + & + & + & & + \\
\hline & prgH & + & + & + & + & + & + & & + \\
\hline & avrA & + & + & + & + & + & + & & + \\
\hline \multicolumn{10}{|c|}{ SPI-2 } \\
\hline & SsaR & + & + & + & + & + & + & & + \\
\hline & ssaB/spiC & + & + & + & + & + & + & & + \\
\hline \multicolumn{10}{|c|}{ SPI-3 } \\
\hline & misL & + & + & + & + & + & + & & + \\
\hline & $m g t B$ & + & + & + & + & + & + & & + \\
\hline \multicolumn{10}{|c|}{ SPI-5 } \\
\hline & PipB & + & + & + & + & + & + & & + \\
\hline & $\operatorname{sop} B$ & + & + & + & + & + & + & & + \\
\hline \multicolumn{10}{|c|}{ SPI-11 } \\
\hline & $C d t B$ & - & + & - & - & - & - & & - \\
\hline \multicolumn{10}{|c|}{ Chromosomal } \\
\hline & sifA & + & + & + & + & + & + & & + \\
\hline
\end{tabular}

\section{Discussion}

Salmonella is an important zoonotic pathogen, and its occurrence in animals constitutes a potential threat to public health. In this study, a low-level occurrence of Salmonella was observed in poultry farms investigated. The isolation rate of Salmonella from this study is lower when compared to similar studies in Maiduguri, northeastern Nigeria (Raufu et al., 2013), Ibadan, southwestern Nigeria (Fashae et al., 2010) and from commercial poultry farms in Nigeria (Fagbamila et al., 2017). These variations may be due to low sample size, types of management practices and the level of biosecurity measures implemented on the farms. Similar studies from other African countries like Ghana, Uganda, and Ethiopia, and Algeria have been reported by Andoh et al. (2016); Odoch et al. (2017); Eguale (2018) and Elgroud et al. (2009), respectively, suggesting chickens are important reservoirs of Salmonella in poultry.
The lower occurrence commonly observed in the European member countries is attributable to the strict implementation of specific control programs such as the strict hygiene and biosecurity practices on the farms. Furthermore, poultry farms are not located in close proximity to one another and movement of personnel and farm equipment between poultry farms is reduced in more developed countries. Such practices are difficult to implement in most developing countries like Nigeria. The low Salmonella prevalence obtained in this study is likely due to a small sample size taken from medium-sized poultry farms studied. The prevalence may be greater among larger farms because it is more difficult for the farmers to adhere to strict farm bio-securities and good farm management practices in such establishments (Adesiyun et al., 2014).

Three Salmonella serotypes comprising of Salmonella Typhimurium, S. Albany, and S. Agama were obtained 
in this study, and Salmonella Typhimurium was the most prevalent serotype (4/7). Salmonella Typhimurium is a common serovar in chickens and most frequently causes foodborne disease worldwide (Freitas et al., 2010; Hendriksen et al., 2011). The serovar is most commonly involved in salmonellosis outbreaks and has been reported by other researchers in Nigeria (Orji et al., 2005; Fasure et al., 2012). Similarly, it has been documented from poultry in Trinidad and Tobago (Adesiyun et al., 2014) and in Algeria (Jakirul et al., 2016). These observations contradicted Fagbamila et al. (2017), who described the role of $S$. Typhimurium in the Nigerian poultry industry as marginal.

Interestingly, one S. Typhimurium from this study shared similar features with one of the strains reported by Kudirkiene et al. (2018) in Ghana, they both belonged to sequence type, ST-19 and carried plasmid replicons IncFII(S)/IncFIB(S) and both lacked resistance genes. But in contrast, the strain from Ghana showed resistance to amino-penicillin and sulphometaxazole classes of antimicrobial agents, while the strain from this study lacked resistance to any antimicrobial agent.

Salmonella Albany is a rarely reported serotype from poultry in Nigeria; it is commonly associated with poultry contamination in Malaysia and other Asian countries as reported by Jeon et al. (2016) and Jajere et al. (2019). Salmonella Agama was first reported in Ibadan, southwest Nigeria from the faeces of Agama lizard (Collard \& Sen, 1960). Recently, however, it is frequently isolated from human and food animals in Nigeria and Africa in general (Orji et al., 2005). This study contradicted previous studies that reported $\mathrm{S}$. Kentucky as the most prevalent serovar in poultry and humans in Nigeria (Muhammad et al., 2009; Raufu et al., 2013). The observed low level of resistance to the majority of the antimicrobials in this study, including those critical for the treatment of salmonellosis in humans such as nalidixic acid and ciprofloxacin, is encouraging. This level of resistance may be the result of cautious antimicrobial utilization at recommended doses for chemotherapeutic and prophylactic control of bacterial infections on poultry farms investigated. These findings contradicted the report of Fashae et al. (2010), who reported a high level of resistance to nalidixic acid and reduced susceptibility to ciprofloxacin. However, our sample size in this study would limit such comparison to a certain limit.

Virulence genes are essential for Salmonella pathogenicity. These genes are vital for the survival of Salmonella during the invasion of the intestinal epithelial cells, replication within macrophages, adherence to, and systemic infection of the host cells. Salmonella pathogenicity islands (SPIs) are chromosomal regions that harbor such genes, and these are involved in Salmonella invasion of and survival within host cells (Ahmed et al., 2018).

The detection of several virulence genes across several virulence loci in conjunction with the identification of chromosomal genes (chromosomal loci) demonstrated that isolates from this study are potential pathogens. Moreover, the identification of invA gene is essential for virulence in Salmonella and is regarded as a standard for Salmonella detection (Mezal et al., 2013). Thus, virulence gene screening corroborated the pathogenic potential of all the isolates.

In this study, MLST was utilized to determine the sequence types; the sequence types obtained for $S$. Typhimurium was ST- 19, which is similar to findings reported by Harb et al. (2018) in Iraq and Jain et al. (2018) in India. Similarly, Zhao et al. (2017) obtained ST-19 as the most frequent genotype that was recovered in pigs and belonged to $S$. Typhimurium. The MLST database has shown ST-19 to be the most widespread genotype of S. Typhimurium; however, it is noteworthy to mention that another strain of $S$. Typhimurium, ST-313, has been predominant in Africa, especially in Nigeria, Kenya, Malawi, Zimbabwe, Uganda, and Ethiopia (Kingsley et al., 2009) but was not detected in this study. Salmonella Albany is a rare serotype from poultry in Nigeria, and the detected sequence type was ST- 5317. This contradicted the S. Albany ST- 292 reported in Colombia from broiler chickens by Castellanos et al. (2018), who indicated the presence of more than one circulating clone. Finally, the sequence type obtained for Salmonella Agama was ST-467.

This study highlights the relative importance of $S$. Typhimurium, S. Albany, and S. Agama as pathogens associated with poultry farm contamination in Ilorin, the north-central region of Nigeria. It equally provided baseline information on the serovar distribution, sequence types (STs), antimicrobial susceptibility, and the virulence gene profiles of the identified serovars. Furthermore, within the context of this study, the absence of resistance to fluoroquinolones and nalidixic acid may correlate with responsible antimicrobial administration on the farms or an overall low level of antimicrobial resistance on the farms in the study area. The isolation of Salmonella on the farms emphasized the need for heightened awareness by national and state authorities to institute measures to monitor and limit 
the spread of Salmonella by instituting effective biosecurity measures on the farms.

Major limitations observed in this study are the small sample size and the small number of farms investigated. However, these gave a narrow interpretation of the isolates collected using the described methodology, which was appropriate for Salmonella isolation and can be utilized for further studies. Therefore, other studies with a larger sample size covering more poultry farms and spread over several regions are recommended.

\section{Acknowledgements}

The authors wish to acknowledge the staff of Veterinary Microbiology Laboratory and Faculty of Veterinary Medicine, the University of Ilorin, for their technical support required for the completion of this work. We also thank Mr. Solomon Oyeniyi of the Department of Geography and Mr Yusuf Durotimi Ibrahim of the Department of Surveying and Geoinformatics (student) for their assistance with the map. We thank the Center for Food Safety and Applied Nutrition (CFSAN) at the U.S. Food and Drug Administration for their support.

\section{Conflict of Interest}

The authors declare that there is no conflict of interest.

\section{References}

Abiodun A, Lloyd W, Lisa M, Bowen L, George J, Stewart-Johnson A, Samlal S \& Rodrigo S (2014). Resistance to antimicrobial agents among Salmonella isolates recovered from layer farms and eggs in the Caribbean region. Journal of Food Protection, 77(12): 21532160.

Achtman M, Wain J, Weill FX, Nair S, Zhou Z, Sangal V, Krauland MG, Hale JL, Harbottle H, Uesbeck A \& Dougan G (2012). Multilocus sequence typing as a replacement for serotyping in Salmonella enterica. PLoS Pathogens, 8(6): 119.

Adesiyun A, Webb L, Musai L, Louison B, Joseph G, Stewart-Johnson A, Samlal S \& Rodrigo, S (2014). Survey of Salmonella contamination in chicken layer farms in three Caribbean countries. Journal of Food Protection, 77(9): 1471-1480.

Ahmed O, Mamman P, Raji M, Kwanashie C, Raufu I \& Aremu A (2017). Distribution of virulence genes in Salmonella serovars isolated from poultry farms in Kwara State, Nigeria. Ceylon Journal of Science, 46(4): 69-76.

Ahmed O, Raji M, Mamman P, Raufu I \& Aremu A (2018). Roles of various virulence and resistance genes associated with Salmonella and methods of their identification. Sokoto Journal of Veterinary Sciences, 16(3): 1-10.

Allard MW, Strain E, Melka D, Bunning K, Musser SM, Brown EW \& Timme RE (2016). Practical value of food pathogen traceability through building a whole-genome sequencing network and database. Journal of Clinical Microbiology, 54(8): 1975-1983.

Andoh L, Dalsgaard A, Obiri-Danso K, Newman M, Barco L \& Olsen J (2016). Prevalence and antimicrobial resistance of Salmonella serovars isolated from poultry in Ghana. Epidemiology and Infection, 144(15): 32883299.

Arredondo-Alonso S, Willems $R$, van Schaik W \& Schürch A (2017). On the (im)possibility of reconstructing plasmids from wholegenome shortread sequencing data. Microbial Genomics, 3(10): 1-8.

Ashton P, Nair S, Peters T, Bale J, Powell D, Painset A, Tewolde R, Schaefer U, Jenkins C, Dallman T, de Pinna E \& Grant K (2016). Identification of Salmonella for public health surveillance using whole-genome sequencing. Peer Journal, doi.10.7717/peerj.1752.

Bankevich A, Nurk S, Antipov D, Gurevich A, Dvorkin M, Kulikov A, Lesin V, Nikolenko S, Pham $S$, Prjibelski A, Pyshkin A, Sirotkin A, Vyahhi N, Tesler G, Alekseyev M \& Pevzner P (2012). SPAdes: a new genome assembly algorithm and its applications to single-cell sequencing. Journal of Computational Biology, 19(5): 455-477.

Carattoli A (2013). Plasmids and the spread of resistance. International Journal of Medical Microbiology, 303(6-7): 298-304.

Castellanos LR, Van Der Graaf-Van Bloois L, DonadoGodoy $P$, León $M$, Clavijo V, Arévalo A, Bernal JF, Mevius DJ, Wagenaar JA, Zomer A \& Hordijk J (2018). Genomic characterization of extended-spectrum cephalosporinresistant Salmonella enterica in the Colombian poultry chain. Frontiers in Microbiology, 9: 1-11. doi: 10.3389/fmicb.2018.02431.

Chen L, Zheng D, Liu B, Yang J \& Jin Q (2016). VFDB 2016: Hierarchical and refined dataset for 
big data analysis--10 years on. Nucleic Acids Research, 44(D1): D694-D697.

Collard P \& Sen R (1960). Serotypes of Salmonella at Ibadan, Nigeria, with special note of the new serotypes isolated from Nigeria. Journal of the Infectious Diseases, 106(7): 270-275.

Ed-dra A, Filali FR, Karraouan B, El Allaoui A, Aboulkacem A \& Bouchrif B (2017). Prevalence, molecular and antimicrobial resistance of Salmonella isolated from sausages in Meknes, Morocco. Microbial Pathogenesis, doi.10.1016/j.micpath.2017.02.042.

Eguale T (2018). Non-typhoidal Salmonella serovars in poultry farms in central Ethiopia: Prevalence and antimicrobial resistance. BMC Veterinary Research, 14(1): 1-8.

Elgroud R, Zerdoumi F, Benazzouz M, Bouzitouna C, Granier S, Fremy S, Brisabois A, Dufour B \& Millemann Y (2009). Characteristics of Salmonella contamination of broilers and slaughterhouses in the region of Constantine (Algeria). Zoonoses and Public Health, 56(2): 84-93.

Emond-Rheault J, Hamel J, Jeukens J, Freschi L, Kukavica-Ibrulj I, Boyle B, Tamber S, Malo D, Franz E, Burnett E, Daigle F, Arya G, Sanderson K, Wiedmann $M$, Slawson $R$, Weadge J, Stephan R, Bekal S, Gruenheid S \& Levesque $R$ (2020). The Salmonella enterica plasmidome as a reservoir of antibiotic resistance. Microorganisms, 8(7): 1-18.

Fagbamila I, Barco L, Mancin M, Kwaga J, Ngulukun S, Zavagnin $P$, Lettini $A$, Lorenzetto $M$, Ayuba $P$, Kabir J, Umoh J, Ricci A \& Muhammad M (2017). Salmonella serovars and their distribution in Nigerian commercial chicken layer farms. PLOS ONE, 12(3): 1-15.

Fashae K, Folasade O, Frank M \& Rene S (2010). 'Antimicrobial susceptibility and serovars of Salmonella from chickens and humans in Ibadan, Nigeria.' Journal of Infection in Developing Countries, 4(8): 484-494.

Fasure A, Deji-Agboola A \& Akinyemi K (2012). Antimicrobial resistance patterns and emerging fluoroquinolone resistant Salmonella isolates from poultry and asymptomatic poultry workers. African Journal of Microbiology Research, 6(11): 2610-2615.

Feasey NA, Dougan G, Kingsley RA, Heyderman RS \& Gordon MA (2012). Invasive non-typhoidal Salmonella disease: An emerging and neglected tropical disease in Africa. Lancet, 379(9835): 2489-2499.

Feldgarden M, Brover V, Haft D, Prasad A, Slotta D, Tolstoy I, Tyson G, Zhao S, Hsu C, McDermott P, Tadesse D, Morales C, Simmons M, Tillman G, Wasilenko J, Folster J \& Klimke W (2019). Validating the AMRFinder tool and resistance gene database by using antimicrobial resistance genotype phenotype correlations in a collection of isolates. Antimicrobial Agents and Chemotherapy, 63(11): 483-419.

Foley SL, Nayak R, Hanning IB, Johnson TJ, Han J \& Ricke SC (2011). Population dynamics of Salmonella enterica serotypes in commercial egg and poultry production. Applied and Environmental Microbiology, 77(13): 42734279.

Food and Agriculture Organization (2018). Livestock and livelihoods spotlight Nigeria: Cattle and Poultry Sectors.

Freitas N, Penha F, Barrow P \& Berchieri J (2010). Sources of human non-typhoid salmonellosis: A review. Brazil Journal of Poultry Science, 12(1): 1-11.

Harb A, Ihab H, Ezat HM, Hayder SK, Tanya L, Mark OD \& Sam A (2018). Occurrence, antimicrobial resistance and whole-genome sequencing analysis of Salmonella isolates from chicken carcasses imported into Iraq from four different countries. International Journal of Food Microbiology, doi. 10.1016/j.ijfoodmicro.2018.07.007.

Hendriksen RS, Vieira AR, Karlsmose S, Wong LF, Jensen $A B$, Wegener $H C$ \& Aarestrup FM (2011). Global monitoring of Salmonella serovar distribution from the World Health Organization Global Foodborne Infections Network Country Data Bank: Results of quality assurance laboratories from 2001 to 2007. Foodborne Pathogens and Disease, 8(8): 887-900.

Hoffmann M, Pettengill J, Gonzalez-Escalona N, Miller J, Ayers S, Zhao S, Allard M, McDermott P, Brown E \& Monday S (2017). Comparative sequence analysis of multidrug-resistant IncA/C plasmids from Salmonella enterica. Frontiers in Microbiology, 8(1459): 1-13.

Huehn S, La Ragione RM, Anjum M, Saunders M, Woodward MJ, Bunge $C$, Helmuth R, Hauser E, Guerra B, Beutlich J, Brisabois A, Peters T, Svensson L, Madajczak G, Litrup E, Imre A, Herrera-Leon S, Mevius D, Newell DG \& 
Malorny B (2010). Virulotyping and antimicrobial resistance typing of Salmonella enterica serovars relevant to human health in Europe. Foodborne Pathogens and Disease, 7(5): 523-535.

Jain P, Sudhanthiramani S, Goutam C, Sangeeta J, Shalini A, Ujjwayni R, Asish M \& Dutta S (2018). Antimicrobial resistance, plasmid, virulence, multilocus sequence typing and pulsed field gel electrophoresis profiles of Salmonella enterica serovar Typhimurium clinical and environmental isolates from India. PLOS ONE, 13(12): 1-16.

Jajere SM, Hassan L, Abdul Aziz S, Zakaria Z, Abu J, Nordin F \& Faiz NM (2019). Salmonella in native "village" chickens (Gallus domesticus): prevalence and risk factors from farms in South-Central Peninsular Malaysia. Poultry Science, 98(11): 59615970.

Jakirul I, Mahbub A, Tanvir A \& Kamrul H (2016). Isolation and identification of Salmonella spp. from broiler and their antibiogram study in Sylhet, Bangladesh. Journal of Applied Biology \& Biotechnology, 4(3): 046051.

Jeon HY, Seo KW, Kim YB, Kim DK, Kim SW \& Lee J (2016). Characteristics of third-generation cephalosporin-resistant Salmonella from. Poultry Science, 98(4): 1766-1774.

Kingsley R, Msefula C, Thomson N, Kariuki S, Holt K, Gordon M, Harris D, Clarke L, Whitehead S, Sangal V, Marsh K, Achtman M, Molyneux M, Cormican M, Parkhill J, MacLennan C, Heyderman R \& Dougan G (2009). Epidemic multiple drug resistant Salmonella Typhimurium causing invasive disease in sub-Saharan Africa have a distinct genotype. Genome Research, 19(12): 2279-2287.

Kudirkiene E, Andoh L, Ahmed S, Herrero-Fresno A, Dalsgaard A, Obiri-Danso K \& Olsen J (2018). The Use of a Combined Bioinformatics Approach to Locate Antibiotic Resistance Genes on Plasmids from Whole Genome Sequences of Salmonella enterica Serovars from Humans in Ghana. Frontiers in Microbiology, 9(1010): 1-14.

Larsen $\mathrm{M}$, Cosentino $\mathrm{S}$, Rasmussen $\mathrm{S}$, Friis $\mathrm{C}$, Hasman $H$, Marvig R, Jelsbak L, Sicheritz-Pontén T, Ussery D, Aarestrup F \& Lund O (2012). Multilocus sequence typing of totalgenome-sequenced bacteria. Journal of Clinical Microbiology, 50(4): 1355-1361.
Li R, Lai J, Wang Y, Liu S, Li Y, Liu K, Jianzhong S \& Congming W (2013). Prevalence and characterization of Salmonella species isolated from pigs, ducks and chickens in Sichuan Province, China. International Journal of Food Microbiology, 163(1): 14-18.

Majowicz SE, Musto J, Scallan E, Angulo FJ, Kirk M, 'Brien SJ, Jones TF, Fazil A \& Hoekstra RM (2010). The global burden of nontyphoidal Salmonella gastroenteritis. Clinical Infectious Diseases, 50(6): 882-889.

McDermott PF, Tyson GH, Kabera C, Chen Y, Li C, Folster JP, Ayers SL, Lam C, Tate HP \& Zhao S (2016). Whole-genome sequencing for detecting antimicrobial resistance in nontyphoidal Salmonella. Antimicrobial Agents and Chemotherapy, 60(9): 55155520.

Mezal E, Stefanova R \& Khan A (2013). Isolation and molecular characterization of Salmonella enterica serovar javiana from food, environmental and clinical samples. International Journal of Food Microbiology, 164(1): 113-118.

Muhammad M, Muhammad L, Mani A \& AG A (2009). A survey of chick mortality at hatching in three selected hatcheries in Jos, Central Nigeria. International Journal of Poultry Science, 8(7): 656-659.

Murugkar HV, Rahman H \& Dutta PK (2003). Distribution of virulence genes in Salmonella serovars isolated from man \& animals. Indian Journal of Medical Research, 117(1): 66-70.

NCBI Resource Coordinators (2017). Database Resources of the National Center for Biotechnology Information. Nucleic Acids Research, 45(D1): D12-D17.

Odoch T, Wasteson Y, L'Abe'e-Lund T, Muwonge A, Kankya C, Nyakarahuka L, Tegule S \& Skjerve E (2017). Prevalence, antimicrobial susceptibility and risk factors associated with non-typhoidal Salmonella on Ugandan layer hen farms. BMC Veterinary Research, 13(1): 1-10.

Orji M, Onuigbo H \& Mbata T (2005). Isolation of Salmonella from poultry droppings and other environmental sources in Awka, Nigeria. Journal of Infectious Diseases, 9(2): 86-89.

Orlek A, Stoesser N, Anjum M, Doumith M, Ellington M, Peto T, Crook D, Woodford N, Walker A, Phan H \& Sheppard A (2017). Plasmid 
classification in an era of whole-genome sequencing: application in studies of antibiotic resistance epidemiology. Frontiers in Microbiology, 8(182): 1-10.

Raufu IA, Ahmed O, Aremu A, Odetokun I \& Raji M (2019). Salmonella transmission in poultry farms: Roles of rodents, lizards and formites. Savannah Veterinary Journal, 2(1): 1-4.

Raufu I, Bortolaia V, Svendsen CA, Ameh JA, Ambali AG, Aarestrup FM \& Hendriksen RS (2013). The first attempt of an active integrated laboratory-based Salmonella surveillance programme in the north-eastern region of Nigeria. Journal of Applied Microbiology, 115(4): 1059-1067.

Raufu I, Hendriksen RS, Ameh JA \& Aarestrup FM (2009). Occurrence and characterization of Salmonella Hiduddify from chickens and poultry meat in Nigeria. Foodborne Pathogens and Disease, 6(4): 425-430.

Robertson J, Yoshida C, Kruczkiewicz P, Nadon C, Nichani A, Taboada E \& Nash J (2018). Comprehensive assessment of the quality of Salmonella whole genome sequence data available in public sequence databases using the Salmonella in silico Typing Resource (SISTR). Microbial Genomics, 4(2): 1-11.

Seemann T (2015). Abricate Github. https://github.com/tseemann/abricate, retrieved 07-02-2020.

Tatusova T, DiCuccio M, Badretdin A, Chetvernin V, Nawrocki E, Zaslavsky L, Lomsadze A, Pruitt K, Borodovsky M \& Ostell J (2016). NCBI prokaryotic genome annotation pipeline. Nucleic Acids Research, 44(14): 6614-6624.

Van T, Nguyen H, Smooker P \& Coloe P (2012). The antibiotic resistance characteristics of nontyphoidal Salmonella enterica isolated from food-producing animals, retail meat and humans in South East Asia. International Journal of Food Microbiology, 154(3): 98106.

Whiley H \& Ross K (2015). Salmonella and eggs: From production to plate. International Journal of Environmental Research and Public Health, 12(3): 2543-2556.

Yang X, Wu Q, Zhang J, Huang J, Chen L, Wu S, Zeng H, Wang J, Chen M, Wu H, Gu Q \& Wei X (2019). Prevalence, bacterial load, and antimicrobial resistance of Salmonella serovars isolated from retail meat and meat products in China. Frontiers in Microbiology, 10.3389/fmicb.2019.02121.

Zankari E, Hasman H, Cosentino S, Vestergaard M, Rasmussen S, Lund O, Aarestrup F \& Larsen $M$ (2012). Identification of acquired antimicrobial resistance genes. Journal of Antimicrobial Chemotherapy, 67(11): 26402644.

Zhang S, Yin Y, Jones M, Zhang Z, Deatherage Kaiser BL, Dinsmore B, Fitzgerald C, Fields P \& Deng $X$ (2015). Salmonella serotype determination utilizing high-throughput genome sequencing data. Journal of Clinical Microbiology, 53(5): 1685-1692.

Zhang X, Payne M \& Lan R (2019). In silico identification of serovar-specific genes for Salmonella serotyping. Frontiers in Microbiology, 10(835): 1-10.

Zhao X, Yang J, Zhang B, Sun S \& Chang W (2017). Characterization of integrons and resistance genes in Salmonella isolates from farm animals in Shandong Province China. Frontiers in Microbiology, 8: 1-10. doi.10.3389/fmicb.2017.01300. 